\title{
Caracterización del programa Usura Cero en el marco del Plan Nacional de Desarrollo Humano de Nicaragua
}

\author{
Ana Amelia Madriz Mengibar ${ }^{1}$ \\ Josseling Lisbeth Osegueda Molina² \\ Aura Lila Guevara Polanco ${ }^{3}$ \\ Anyolly Denisse Armas Hernández ${ }^{4}$ \\ Beverly Castillo Herrera ${ }^{5}$
}

\section{RESUMEN}

Este artículo presenta de manera general la Problemática del Desarrollo y la Participación Ciudadana en América Latina, y de manera específico el caso de Nicaragua. Antes de entrar a discutir esta temática se presenta una breve recopilación teórica sobre los modelos de desarrollo que han estado vigentes en las últimas décadas en la región, sus afectaciones positivas y negativas. Está claro que han surgido diferentes maneras para alcanzar el desarrollo y afrontar la desigualdad y la pobreza, en Nicaragua el Gobierno de Reconciliación y Unidad Nacional (GRUN) ha implementado Usura Cero, un programa de estrategia económica que consiste en microcréditos para mujeres. Este funciona bajo el Plan Nacional de Desarrollo Humano con el fin de promover el empoderamiento de la mujer, y luchar contra la pobreza. Usura Cero tiene una estrategia organizativa que ha venido evolucionando con los años, con el fin de restituir los derechos de las personas y promover un desarrollo integral y sostenible, con una participación incluyente.

Palabras claves: Nicaragua, desarrollo, microcréditos, Usura Cero, PNDH.

Recibido: 17 de noviembre de 2016

Aceptado: 16 de diciembre de 2016

1 UNAN-Managua/FAREM-Estelí. Correo electrónico: annie1712@gmail.com 2 UNAN-Managua/FAREM-Estelí. Correo electrónico: josseling.osegueda@gmail.com

3 UNAN-Managua/FAREM-Estelí. Correo electrónico: guevarap@hotmail.com 4 UNAN-Managua/FAREM-Estelí. Correo electrónico: anyolihernandez@yahoo.es

5 Doctora en Ciencias Sociales de la Universidad de Zulia. Docente titular de UNAN-Managua/FAREM-Esteli. Correo electrónico: beverly.castillo@yahoo.com 


\title{
Characterization of the Usura Cero program in the framework of the National Plan of Human Development of Nicaragua
}

\begin{abstract}
This article presents in a general way the Problems of Development and Citizen Participation in Latin America, and in a deeper way the situation in Nicaragua. Before discussing this topic, a brief theoretical compilation about the development models that have been in force in the last decades in the region, its positive and negative effects, is presented. It is clear that different ways have emerged to achieve development and address inequality and poverty, in Nicaragua the Government of Reconciliation and National Unity (GRUN) has implemented Usura Cero, an economic strategy program consisting of microcredit for women. It works under the National Human Development Plan to promote the empowerment of women, and to fight against poverty. Usura Cero has an organizational strategy that has been evolving over the years, in order to restore the rights of people and promote integral and sustainable development, with an inclusive participation.
\end{abstract}

Keywords: Nicaragua, development, microcredit, Usura Cero, PNDH. 


\section{INTRODUCCIÓN}

El presente artículo aborda la problemática del desarrollo y la participación ciudadana en América Latina y Nicaragua, destacando en primer lugar, las diferentes teorías que se han contextualizado en las últimas décadas y los factores políticos, económicos, sociales y culturales que han ayudado a reprimir el desarrollo en estos países. Entre estos se menciona la dependencia que caracteriza a la región dejando más resultados negativos que positivos. De estos parten las potencias mundiales, para llamarlos como países subdesarrollados.

Si bien, existe un relativo crecimiento en América Latina, pero este se encuentra muy atrás en términos de ingresos, calidad de vida, y en desigualdad, la situación es más dura. De hecho, la brecha entre los que tienen recursos y los que no tienen sigue creciendo en muchas partes del mundo. Por otro lado, países como Nicaragua, Haití y Honduras, al igual que países de África subsahariana seguirán dependiendo financieramente de instituciones de crédito como el Fondo Monetario Internacional (FMI), y otras ONG. Pero algo distinto está sucediendo en los últimos años específicamente en Nicaragua, ya que su gobierno ha entendido que el desarrollo no solo comprende el crecimiento económico, sino también, el desarrollo integral de las personas, donde todos y todas están involucrados en los distintos procesos con el fin de mejorar las condiciones de vida humana.

En lo que refiere a participación son notables los progresos para mejorar la transparencia de la información pública y por establecer nuevos mecanismos de participación en la elaboración de políticas públicas. La calidad de las leyes, en general, es eficiente, pero no lo suficiente para que se produzcan resultados tangibles. Existen países latinoamericanos que se han tomado seriamente el tema de participación, entre ellos destacan Nicaragua, Bolivia, Ecuador, y Perú, quienes han aprobado leyes que obligan a los gobiernos subnacionales a establecer mecanismos institucionalizados de participación ciudadana para la aprobación y seguimiento de planes de desarrollo enfocados en la temática.

Este articulo muestra una breve caracterización del Programa Usura Cero, enmarcado en el enfoque de desarrollo y participación ciudadana definido en el Plan Nacional de Desarrollo Humano 2007-2016 de Nicaragua.

\section{Conceptos teóricos de desarrollo}

En este artículo se han definido tres, de los principales enfoques de Desarrollo que se están implementando en América Latina en los últimos veinte años, considerando que la causa del denominado "subdesarrollo" trasciende a aspectos netamente económicos, para incluir otras variables como son: educación, salud, vivienda, relaciones de género, prácticas colectivas, recursos materiales y simbólicos, entre otros.

\section{Desarrollo con Equidad}

Desarrollo con equidad es ante todo, una estrategia de desarrollo que implica conjugar, a través de decisiones de autoridad y prácticas colectivas acordes, crecimiento, cambios y reajustes estructurales en la economía, en las relaciones sociales y en el acceso de diferentes sectores de la población a recursos, en una perspectiva de mediano y largo plazo. Involucra, por lo tanto, cambios en las relaciones de poder entre actores, en cuanto el ejercicio del poder se hace siempre a través de la movilización de recursos materiales y simbólicos, fácticos e institucionales, que se encuentran desigualmente distribuidos. (Vilas, 2008)

Para lograr procesos exitosos de desarrollo y equidad social, todo Estado debe modificar las relaciones de dominación/subordinación que se generan al interior de la sociedad. Esto sólo es posible con el involucramiento de los actores que persiguen esos objetivos en diferentes niveles e instancias de dirección y gestión. 


\section{Desarrollo Sostenible o Sustentable}

El Desarrollo sustentable se trata, en definitiva, de un replanteamiento del actual modelo de desarrollo, tradicionalmente basado en parámetros cuantitativos decrecimiento económico puro y duro, que no ha tenido en cuenta los efectos negativos que nuestras actividades socioeconómicas tienen sobre el entorno natural, las sociedades contemporáneas, que se encuentran en cualquier parte del planeta, y las sociedades del futuro, las cuales tienen el derecho a recibir un medio ambiente en condiciones tales que puedan ejercer sus propias opciones de vida. Se trata de integrar las esferas de lo ambiental, lo económico y lo social. (Felpudos, 2012)

La concepción actual del desarrollo sustentable ha implicado una evolución social, política y hasta económica, para entender su estructura presente es necesario hacer un recorrido histórico por el conjunto de movimientos y actores que han alimentado este concepto a lo largo del tiempo. La sostenibilidad es necesaria para enfrentarse a los retos globales de la actualidad, lo que se pretende con el desarrollo sostenible es alcanzar cierto equilibrio entre los actores sociales, políticos y ambientales para garantizar la calidad de vida que se ha buscado durante décadas, lo difícil es encontrar este equilibrio cuando no se hace énfasis en la participación con equidad de manera global.

\section{Desarrollo Humano (PNDH)}

El paradigma de desarrollo humano que apareció a finales de los años ochenta representó un cambio radical por dos razones. En primer lugar, porque cuestionaba la premisa utilitaria que servía de fundamento a gran parte de la economía del desarrollo. A partir sobre todo de la obra profundamente innovadora de Amartya Sen, el proceso de desarrollo se ve como un proceso de ampliación de las "capacidades" de las personas y no como un aumento de la utilidad y del bienestar y satisfacción económicos. Es decir, el objetivo del desarrollo no es incrementar el producto sino propiciar que la gente disponga de una gama mayor de opciones, que pueda hacer más cosas, vivir una vida más larga, eludir enfermedades evitables, tener acceso a la reserva mundial de conocimientos, etcétera. (Griffin, 1998)

El desarrollo es entonces mucho más que el crecimiento económico, que constituye sólo un medio para que cada persona tenga más oportunidades. Para que existan más oportunidades lo fundamental es desarrollar las capacidades humanas: la diversidad de cosas que las personas pueden hacer o ser en la vida. Las capacidades más esenciales para el desarrollo humano son disfrutar de una vida larga y saludable, haber sido educado, acceder a los recursos necesarios para lograr un nivel de vida digno y poder participar en la vida de la comunidad.

\section{METODOLOGÍA}

Este artículo es el resultado de una investigación documental sobre el Programa Usura Cero que se implementa en Nicaragua desde inicios del año 2007. Este programa se concibe como un proyecto piloto de crédito dirigido a mujeres trabajadoras, ha recorrido desde entonces un largo camino con logros visibles como parte de la política de restitución de derechos que impulsa el Gobierno Sandinista. Sus propias beneficiarias testimonian los avances del programa que se traducen en una cobertura de 144 municipios, 90 mil socias, 150 mil créditos otorgados, en más de tres mil barrios de todo el país.

Las mujeres trabajadoras que participan del Programa están contribuyendo a dinamizar la economía del país y según la directora de Usura Cero, Leonor Corea, ellas mueven más de 200 millones de córdobas mensuales y hasta la fecha se han entregado unos 800 millones de córdobas, en créditos solidarios. 


\section{Caracterización del contexto donde se ubica el objeto de estudio}

Nicaragua, oficialmente República de Nicaragua, es un país de América ubicado en el istmo centroamericano. Tiene una superficie de 130,370 km, es el país más grande de Centro América, limita al norte con Honduras, al sur con Costa Rica, al oeste con el océano Pacífico y al este con el mar Caribe. En cuanto a límites marítimos, en el océano Pacífico colinda con El Salvador, Honduras y Costa Rica; mientras que en el mar Caribe colinda con Honduras, Colombia y Costa Rica. Su capital es Managua, políticamente es una República presidencialista y unitaria compuesta por 15 departamentos y 2 regiones autónomas (RAAS Y RAAN). (Benavidez, 2012)

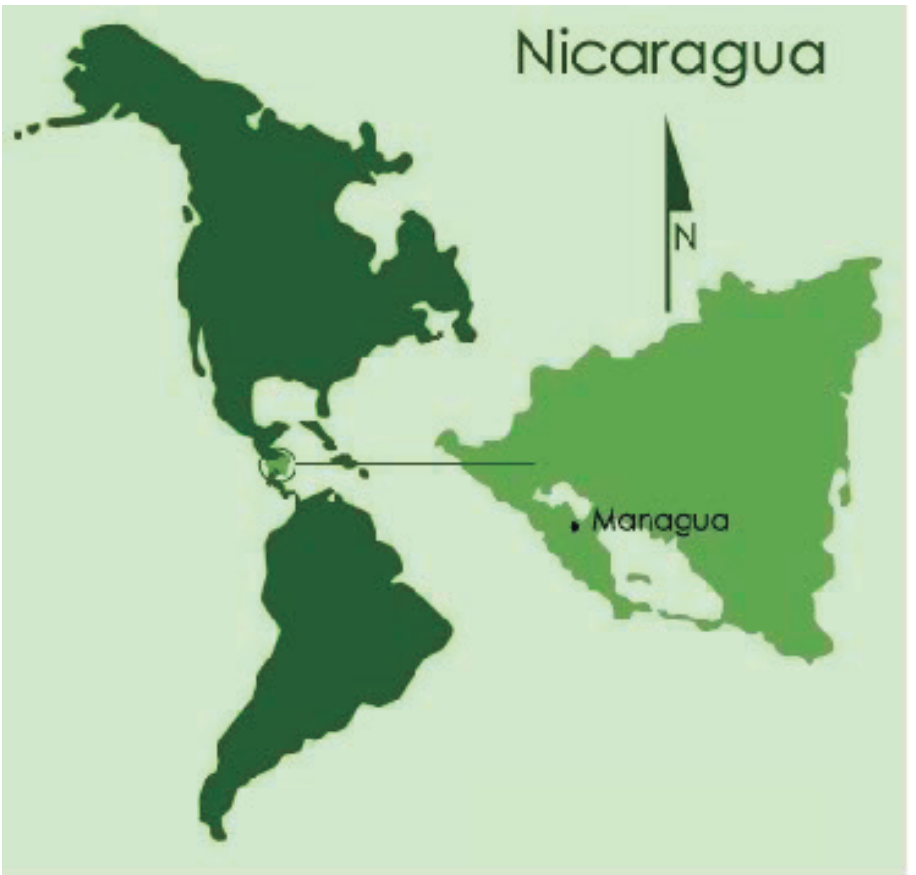

Fuente: http://www.taringa.net/post/info/9012136/NicaraguaMi-Pais-te-invito-a-conocerlo.html

Usura Cero es un programa de microcrédito que crea oportunidades para que las mujeres, organizadas en grupos, puedan beneficiarse de préstamos para mejorar pequeños negocios o realizar nuevos. Hasta la fecha se han acreditado más de 500 mil créditos en departamentos como Managua, León, Estelí entre otros con 144 municipios aproximadamente. Estos préstamos se realizan con un interés mínimo de $5 \%$, con el compromiso de reintegrar el dinero en un plazo determinado para ayudar a otras que también requieran de ayuda financiera. (Corea, 2014)

\section{Etapas de la investigación}

En el transcurso de esta investigación documental se consultaron diversas fuentes de información, entre ellas la Biblioteca Urania Zelaya de la Facultad Regional Multidisciplinaria FAREM-Estelí, la Biblioteca Municipal Samuel Meza de Estelí, y la pequeña colección de libros de Juan Manuel Guevara. Además, visitamos distintas páginas webs.

El instrumento de recolección de datos que se utilizó fue la entrevista. La aplicación de esta técnica permitió una relación directa con los coordinadores y facilitadores de del Programa Usura cero, de igual manera se entrevistó a dos beneficiarias del programa. Además, se consideró adecuada la técnica de observación, la cual es, según Bussot (1988), la forma de percibir hechos o fenómenos en forma directa y facilita la confiabilidad deseada en el proceso, ya que permite describir de manera directa los acontecimientos, así como constatar lo que ocurre.

Después de haber aplicado los instrumentos de la investigación se analizaron las entrevistas a: coordinadores, facilitadores y beneficiarias del programa, con el fin de aclarar dudas y enriquecer con información empírica.

\section{DESARROLLO}

\section{Contexto: Los Programas de Crédito para Mujeres en América Latina}

En los últimos años se han producido grandes e importantes modificaciones respecto al papel de las mujeres en la sociedad: la esperanza de vida de las mujeres es mayor, tienen menos hijos, aumentan sus 
niveles de estudios, participan en alta proporción en el mercado del trabajo e incursionan con más éxito en campos antes marcados por el predominio masculino, sin embargo esto no se ha traducido en mayor equidad y particularmente, para efectos de este trabajo, en el "acceso" de las mujeres a los recursos económicos. Efectivamente, la evidencia muestra que existe un sesgo negativo hacia las mujeres en el acceso a los servicios crediticios como también en las condiciones bajo las cuales lo hacen.

Hernández (2016) expresa que América Latina es la región que presenta las mayores brechas económicas en el mundo. El 5\% más rico recibe el 25\% del ingreso nacional mientras que el $30 \%$ más pobre recibe menos del 7,5\%. Esta autora menciona que si vamos detallando las desigualdades de ingresos, se reconocen además diferencias en los ingresos per cápita entre hombres y mujeres en igualdad de condiciones, donde el ingreso de las mujeres es en promedio un $47 \%$ el ingreso de los hombres 10 , destacando que entre una tercera y cuarta parte de los hogares de América Latina dependen de este único ingreso femenino.

El sector financiero en América Latina - particularmente los servicios de crédito - continúa con un enfoque de evaluación basado en características y necesidades de los hombres, sin considerar que las distintas realidades y condiciones de trabajo de muchas mujeres no se ajustan a estos parámetros y esquemas para la obtención de un crédito, por lo que quedan generalmente excluidas.

En Colombia existe el Programa de Créditos para mujeres cabezas de familia. La idea surgió como respuesta a la situación del país en el año 2001, según la cual un $24 \%$ de hogares son manejados por mujeres, y son ellas las que velan por el sustento de sus familias. De este grupo de hogares, el 7\% vive en la miseria, es decir, carecen de servicios públicos, no alcanzan a ganar un salario mínimo y sus hijos no van estudiar.
En el caso de Venezuela, el presidente de la República, Nicolás Maduro, activó el programa “Soy Mujer”, el cual estará orientado en financiar proyectos familiares y colectivos a las mujeres emprendedoras del país. El Ejecutivo entregó más de 13 millones de bolívares del total de la cantidad asignada a ocho proyectos productivos de mujeres provenientes de diferentes regiones del territorio nacional que estaban presentes en la actividad.

\section{El Enfoque de Desarrollo Humano en el Modelo Cristiano, Socialista y Solidario enmarcado en Nicaragua ${ }^{1}$}

Al describir un Programa de Desarrollo en Nicaragua es importante considerar que todos están enmarcados en la política pública del país basada en el Modelo Cristiano, Socialista y Solidario del Gobierno de Reconciliación y Unidad Nacional (GRUN). Este modelo se basa en el ideal socialista que brinda oportunidades de realización y producción a todas y todos, construyendo una sociedad más igualitaria mediante la redistribución de ingreso y la riqueza, a partir del apoyo a los pobres y la micro, pequeña y mediana producción, con programas gubernamentales que transforman de manera estructural la realidad de las y los nicaragüenses, con educación y salud gratuita y universal, capitalización de los pobres y subsidios para atender las necesidades básicas de las familias, sobre todo su seguridad alimentaria y nutricional. El modelo también es socialista al construir el Poder Ciudadano como expresión de organización y movilización del pueblo con plena participación y decisión permanente en la construcción de la democracia directa.

Es solidario porque las políticas públicas y prácticas solidarias parten de la realidad de las familias nicaragüenses, sus necesidades, sus aspiraciones y su situación actual, así como el impacto de los procesos

1 GRUN. (2012). Plan Nacional de Desarrollo Humano 2012-2016. Managua. Obtenido de http://www.pndh.gob.ni/ documentos/pndhActualizado/pndh.pdf 
socioeconómicos y políticas públicas actuales y potenciales sobre las familias nicaragüenses, especialmente las más pobres. Esta solidaridad estructural se combina con solidaridad para toda familia víctima de desastres naturales, así como para todas las personas en situación de desamparo. También se manifiesta en la responsabilidad social compartida de toda la sociedad para el cuido de la infraestructura económica y social del país, así como para todos los bienes públicos comunes.

El modelo tiene un supuesto de que la única manera de transformar Nicaragua es transformando a las y los nicaragüenses, y los logros 2007-2011 se ven en más de 123 mil mujeres pequeñas empresarias capitalizadas en el país con el Programa Usura Cero, entre otros logros, son ejemplos de cómo el modelo llevó a la recuperación de valores, a la restitución de derechos y el fortalecimiento de capacidades de las y los nicaragüenses.

El PNDH busca crear condiciones que faciliten la plena realización de las y los nicaragüenses en un país soberano e independiente, en unión con los hermanos centroamericanos, caribeños y latinoamericanos.

La estrategia productiva para el quinquenio 2012-2016 se basa en la continuidad y fortalecimiento del modelo de atención integral a la micro y pequeña producción rural y urbana, reconociendo y fortaleciendo las diferentes capacidades de las familias nicaragüenses en sus diferentes formas de participar en la economía nacional, para aumentar los rendimientos, la producción y el valor agregado, así como los ingresos familiares que permitan ir superando la pobreza, las desigualdades y debilidades que continúan afectando a la economía familiar, comunitaria y cooperativa.

\section{Estrategia Organizativa del Programa Usura Cero en Nicaragua}

Las estrategias del programa se corresponden con las prioridades y las líneas estratégicas para la mujer que impulsa el gobierno, como es acciones orientadas a la restitución de los derechos, mediante acciones de comunicación, capacitación, organización y acceso a recursos de apoyo directo a las mujeres para que desde sus comunidades se inserten a la vida económica, productiva, social y política.

Para favorecer la sostenibilidad del programa se previó destinar un mayor porcentaje de los recursos a nivel nacional esperando mayor impacto en la calidad de vida de las mujeres. El gran desafío fue transitar, de un modelo asistencialista (idea dinámica y plástica de la intervención y de la atención, como un sistema orientado a las necesidades reales y cambiantes de las personas mayores, adelantándonos y minimizando en lo posible la repercusión de dichos cambios), a otro, que genere crecimiento económico sostenible, priorizando la creación de capacidades, inversiones sociales, reducción de vulnerabilidades, y fomento del capital social y mejores condiciones de productividad y competitividad.

El programa adopta estrategias e iniciativas impulsadas en los niveles regionales y municipales por organizaciones locales a fin de apoyar el establecimiento y fortalecimiento de redes, el empoderamiento económico de las mujeres y el ejercicio de sus derechos sexuales y reproductivos. Esto incluye acciones de incidencia para que las necesidades de mujeres sean incorporadas en los presupuestos municipales y nacionales. El programa propone el mayor peso de sus actividades y asignaciones presupuestarias al trabajo directo con las mujeres en los municipios seleccionados concertando acciones con instituciones y programas del gobierno dirigidos al combate a la pobreza y con otras experiencias de la población relacionadas a temas como microempresas, entre otras.

Parte de los esfuerzos para restituir los derechos de las mujeres, en este caso mejorando el acceso al crédito, con tasas de interés justas y mecanismos sencillos que permitieran financiar los pequeños negocios como 
pulperías, cominerías, talleres de costura, etc., que han venido instalándose por décadas en los barrios de todo el país y que en su mayoría están en manos de las mujeres, quienes a su vez atienden sus negocios y cuidan a sus hijos. También en el programa usura cero se incorporan a las mujeres que recorren las calles y las comunidades vendiendo su mercadería y las que en los pequeños tramos de los mercados con la venta diaria de sus productos garantizan el sustento de sus hijos.

Para estas miles de mujeres, sin diferencias políticas, de edad o religiosas se les planteó la conformación de una sociedad entre ellas, con principios básicos como son la solidaridad entre los grupos solidarios que ellas organizan y la confianza del Gobierno de Reconciliación y Unidad Nacional al depositar en sus manos los créditos. Esa solidaridad y esa confianza se ratifican en cada entrega de créditos.

\section{Descripción del Programa de Crédito Usura Cero} Nicaragua

El gobierno actual del Comandante Daniel Ortega Saavedra en aras de reducir el índice de pobreza estableció como parte de la estrategia económica la creación de un fondo de aproximadamente C\$2, 000,000 para ofrecerlos en concepto de préstamos, a través del programa usura cero, que fue creado el 2 de agosto del 2007 mediante el decreto presidencial No.75-2007 y su modificación mediante el Decreto Presidencial No.7-2008, el cual establece que la conformación, organización y dirección de dicho programa corresponde al MIFIC.

Las políticas socio-económicas promovidas por el Gobierno Sandinista han dado lugar al desarrollo de la economía de las familias, a través del Programa Usura Cero impulsado desde el 2007 se ha llegado a miles de emprendedores de nuestro país, permitiéndoles mejorar las condiciones económicas de mujeres luchadoras y trabajadoras.
A través de la creación de pequeños grupos solidarios conformados por mujeres se ha venido otorgando financiamientos para sus negocios familiares, dado respuesta a la gran demanda de muchas protagonistas las que por años no pudieron optar a un beneficio de este tipo debido a su condición económica y falta de garantías.

\section{Objetivos del programa Usura Cero}

El objetivo general del programa usura cero, es el de impulsar el desarrollo de las mujeres trabajadoras y reduciendo las barreras de acceso a las fuentes formales de financiamiento, en especial cuando no se pueden presentar pruebas de ingreso y garantías que respalden los créditos. El programa de micro crédito usura cero contribuye en forma paralela con otros Programas del Gobierno, para el alcance de dos de los objetivos del Milenio:

a. Erradicar la pobreza extrema, cuya meta es reducir a la mitad, entre 1990 y 2015, el porcentaje de personas cuyos ingresos sean inferiores a 1 dólar por día.

b. Promover la igualdad entre los géneros y el empoderamiento de la mujer, a través de proveer los recursos necesarios para que ellas puedan tener autonomía tanto a nivel personal, familiar como empresarial.

\section{Bases del programa Usura Cero:}

El sector económico a financiarse serán micro empresas o mujeres asociadas del sector: comercio y bienes y servicios.

- Los montos que se otorgan en créditos son los siguientes: \$266.00; \$223.00; C\$180.00; \$133.00 y $\$ 90.00$. Estos montos pueden variar a partir de análisis que se realicen con los perfiles de negocios.

- La tasa de interés es del 5\% anual sobre saldo, más mantenimiento de valor. 
- Los plazos del crédito son de: 3 meses, 4 meses; 6 meses y 8 meses. Los que deberán ser cancelados en cuotas semanales por la coordinadora electa de cada grupo solidario.

- Los planes de negocios pueden presentarse individual o por grupo solidario.

- Cuando finalice su crédito podrán acceder a uno o nuevo.

- El interés moratorio será de 2.5\%, como prevención. Cada crédito implica una capacitación, qué tipo de capacitación reciben las beneficiarias del Programa y cómo las socias lo han asimilado.

Requisitos para ingresar al programa de Micro crédito "Usura Cero". La tasa de interés es del cuatro por ciento anual (GRUN-MIFIC, 2008, págs. 1-2).

\section{A. Ingreso en los barrios}

- Mujeres mayores de 18 años.

- Que tengan cédula de identidad vigente.

- Que residan en barrios ubicados en zonas urbanas.

- Dispuestas a organizarse solidariamente en grupos de 5 a 10 personas, que no habiten en la misma vivienda, no sean familiares y estén dispuestas a firmar el acta de compromiso. Con ingresos individuales netos menores de la canasta básica.

- Que manifiesten interés de emprender un negocio o ya lo tengan conformado y quieran mejorarlo.

- Que asuman el compromiso de recibir al menos dos capacitaciones y elaborar su plan de negocios.

- Que asuman el compromiso de entregar semanalmente en los locales definidos las cuotas de amortización del préstamo hasta su cancelación.

- Que tengan buen record de crédito y un nivel de endeudamiento no mayor al 50\% del monto recibido por la otra institución.

\section{B. Ingreso a través de mercados, asociación}

- Mujeres mayores de 18 años.

- Que tengan cédula de identidad vigente.
- Que manifiesten interés de emprender un negocio o ya lo tengan conformado y quieran mejorarlo.

- Que estos negocios se encuentren ubicados en zonas urbanas atendidas por el programa.

- Dispuestas a organizarse solidariamente en grupos de 5 a 10 personas, que no habiten en la misma vivienda, no sean familiares y estén dispuestas a firmar el acta de compromiso.

- Con niveles de venta diario como máximo de C $\$ 15,000$.

- Que asuman el compromiso de recibir al menos dos capacitaciones y elaborar su plan de negocios.

- Que asuman el compromiso de entregar semanalmente en los locales definidos las cuotas de amortización del préstamo hasta su cancelación.

- Que tengan buen record de crédito y un nivel de endeudamiento no mayor al 50\% del monto recibido por la otra institución crediticia.

- Impulsar desde sus negocios la defensa de la política de no alza al consumidor

El INATEC tiene bajo su responsabilidad desarrollar el plan de capacitación del programa usura cero estructurado en dos fases:

- En la primera fase: participan todas las mujeres que llenan su ficha de inscripción y que son verificadas por el Ministerio de Fomento Industria y Comercio.

- En la segunda fase: la capacitación versa sobre temas directamente relacionados con elementos básicos de administración de pequeños negocios y está dirigido a las mujeres cuyos planes de negocios fueron analizados y aprobados por el comité de crédito del programa.

\section{Principales Resultados del Programa Usura Cero}

Leonor Corea, directora del Programa muestra casos emblemáticos de los resultados obtenidos, subrayó que hay muchas compañeras que no tenían un negocio y gracias a este proyecto arrancaron: Nos decían las compañeras de pulperías que se han abierto, pequeñas 
pulperías que han arrancado en los barrios, y que después de uno, dos, tres créditos, las encontramos que ya trabajan con su marido, que efectivamente su nivel de venta ha mejorado, que además de abarrotes están vendiendo carne, pollo, y todo eso genera más ingresos, recalcó.

A 37 Años del Triunfo de la Revolución Popular Sandinista y a nueve años de haber realizado nuestro Presidente de la República, Comandante Daniel Ortega Saavedra, el Lanzamiento del Programa Usura Cero, los principales avances que se tienen son (Nicaragua Triunfa, 2010):

- La atención con créditos a 80,649 mujeres para que pudieran mejorar sus pequeños negocios, en sus barrios, en los mercados, o bien las que recorren calles y comunidades de los municipios vendiendo sus productos.

- Estos negocios han sido principalmente pulperías, comiderías, costureras, negocios que se dedican a la elaboración y venta de piñatas, pequeñas panaderías, pequeños salones de belleza, tortillerías, refresquerías, pequeños cafetines o kioskos que instalan en parques, calles, etc. Se financian todos los negocios que ellas consideran les va a ayudar a mejorar sus ingresos.

- Con este financiamiento recibido a plazos máximos de 8 meses y pagos semanales, las mujeres han logrado poco a poco, paso a paso, comprar a mejor precio los productos para sus negocios y mejorar o cambiar los equipos como máquinas de coser, cocinas, etc.

- Algunas de ellas han iniciado sus negocios, generando un mayor ingreso en su familia. En este grupo tenemos a 25,167 mujeres.

- El $40.58 \%$ de las mujeres atendidas han recibido dos y hasta seis créditos. En la medida que van finalizando su crédito anterior.

- Las mujeres han ratificado la sociedad, entre ellas al organizarse en 18,769 Grupos Solidarios, y estos a su vez con el Gobierno de Reconciliación y
Unidad Nacional, al recibir 123,896 créditos.

- En cada crédito recibido, cada integrante del Grupo Solidario firma y se compromete en presencia de todas las integrantes a implementar sus negocios y efectuar sus pagos semanales.

- El financiamiento total que han recibido las mujeres es de C\$657, 449,650.00. Esto ha sido posible a partir de tener un 94\% de recuperación en el capital semilla asignado al Programa, a través de los presupuestos anuales, así como el apoyo y solidaridad de Gobiernos amigos como el de la República Bolivariana de Venezuela y el de China Taiwán, que también han confiado en las miles de mujeres nicaragüenses.

- El crédito ha sido llevado a 2,860 barrios de 145 municipios del país. Esto ha facilitado la atención hacia las mujeres, pero también les ha permitido aprovechar mejor el financiamiento recibido, porque no tienen que utilizar parte de sus ganancias en gastos de transporte para realizar sus pagos semanales en las cabeceras departamentales, lo que les ocasionaba también atrasos en la atención a sus negocios hasta de un día de trabajo.

- En el caso particular de los mercados de Managua, la coordinación interinstitucional con la Nueva COMMEMA, ha permitido que el Programa las atienda en cada mercado. Esto hace más accesible el crédito hacia las mujeres.

- También la coordinación con INATEC, desde que iniciara el Programa ha permitido de manera conjunta implementar con cada crédito capacitaciones sobre temas de: género, autoestima, higiene y salud, así como de principios básicos para administrar mejor sus pequeños negocios.

- Estos contenidos han permitido que en la medida que reciben más créditos los Grupos Solidarios, una vez que pagan el anterior, los temas van siendo implementados por ellas en sus negocios y en su familia. 
Participación Ciudadana en el Programa Usura Cero

El programa Usura Cero, desarrollado desde el 2007 por el Gobierno Sandinista para apoyar el empoderamiento socioeconómico de las mujeres en nuestro país, ha llegado a más de 180 mil protagonistas a nivel nacional. El programa comenzó en Managua con la atención a cuatro mil 200 mujeres, cifra que se incrementó a más de 120 mil compañeras en el periodo de 2007 a 2011, las cuales recibieron más de 200 mil créditos. (Cerón, 2016)

Lo que va de 2016 se han entregado aproximadamente 500 mil créditos, los cuales son utilizados en diversos negocios que emprenden las protagonistas y que ayudan a reducir los niveles de pobreza en nuestro país. Para el objetivo en este 2016 es atender 115 mil mujeres y entregar 130 mil créditos en todos los municipios nicaragüenses. La intención es que las protagonistas pueden invertir en diferentes rubros, como el turismo, sector que el programa ha comenzado a atender. (Cerón, 2016)

En el departamento de Estelí, la evolución de este Programa es significativa, en 2008 se iniciaron con 1404 beneficiadas, en la actualidad son 5543 mujeres quienes gozan de este préstamo. Claudia González, quien es una de las beneficiadas por el programa Usura Cero, explicó que en tres ocasiones ha recibido financiamiento por parte del gobierno. Ello le ha permitido superarse y establecer su propio negocio.

A su vez las protagonistas del programa Usura Cero deben cumplir con el pago de las cuotas establecido, dado que el éxito de la iniciativa depende de la responsabilidad de cada una de las mujeres que han recibido este apoyo. De esta manera las posibilidades de financiamiento se pueden extender en todo el país y así incrementar la ayuda a otras emprendedoras. (La voz del sandinismo, 2016).
Para el otorgamiento de estos préstamos, se crean grupos de cinco a 10 integrantes y se les otorga a ese bloque una cantidad de dinero, que se reparten entre ellas, por lo que cada una tiene una cifra a reintegrar, pero cuando existen casos de enfermedad u otra causa mayor, entonces las restantes del grupo ponen su parte como un préstamo. La recuperación del dinero prestado está en un 98 por ciento, lo que significa que ha sido efectivo, porque hay socias de Usura Cero con más de cinco créditos, algunas hasta 18 , y cuando consideran que ya pueden continuar solas, porque su negocio prosperó, lo hacen saber. (La voz del sandinismo, 2016)

Se contempla la incorporación de nuevas protagonistas a través de la realización de asambleas en barrios de 140 municipios para promover la organización de grupos solidarios, conformados principalmente por mujeres que se dedican a negocios productivos. También se coordinará con los gobiernos locales para que las protagonistas que participan en los cursos de las escuelas de oficios conozcan los requisitos a seguir en la organización de grupos solidarios. La idea es que estas puedan conocer los requisitos de implementación de sus negocios con Financiamiento del Programa Usura Cero. (El 19 digital, 2015)

Además, se promoverá el desarrollo de capacidades de las protagonistas. Esto se hará en coordinación con INATEC, capacitando a todas las protagonistas que ingresan por primera vez al programa. El objetivo será atender a 9,000 mujeres con el Curso de "Administración de Pequeños Negocios", definiendo sus metas de cumplimiento para avanzar en la Prosperidad de sus Negocios. Otra de las acciones a desarrollar es la promoción de enlazamientos productivos entre Protagonistas del Programa Usura Cero. Esto se hará en coordinación con el MEFCCA impulsando reuniones mensuales entre Protagonistas de los Programas de nuestro Gobierno de Reconciliación y Unidad Nacional para que de acuerdo a las características de los Negocios y Productos, puedan fortalecer sus Relaciones Comerciales. De la misma manera, se 
promoverá la participación de las Protagonistas del Programa Usura Cero en todas las Ferias Municipales y Departamentales; así como también en las ferias locales y nacionales que organizan los Gobiernos Locales, MEFCCA e INTUR. (E1 19 digital, 2015)

\section{Sostenibilidad del Programa Usura Cero}

ElPrograma Usura cero ha demostrado su sostenibilidad al lograr mantenerse en pie desde hace siete años que surgió como un proyecto sencillo con la idea de ayudar a mujeres con negocios pequeños. En la actualidad, Usura Cero da más de C\$20,000 Córdobas a cada mujer, de esta manera no solo se mejora la economía, también se construye una sociedad con valores fuertes, donde las mujeres se sienten apoyadas con su Grupos Solidarios. Este programa afecta tanto a familias como comunidades completas, ya que se vuelve un proceso de transición donde la mayor parte de las mujeres beneficiadas van generando cambios desde su interior hasta lo externo, afectando positivamente a quienes les rodean.

Usura Cero es sostenible porque se encargan de capacitar a cada una de las mujeres beneficiadas en la administración, organización y mercadeos de sus negocios, volviéndolas mujeres eficaces y productivas, a la vez que fomentan valores éticos, morales y cristianos, que comprometen a las beneficiadas a cumplir con el pago de sus cuotas y sus metas, siendo estas generadores de empleos y oportunidades, dando rentabilidad al programa.

\section{CONCLUSIONES}

Al inicio de este artículo se planteaban los tres modelos de desarrollo que han tenido mayor repercusión en Latinoamérica, y es interesante como estos modelos están estrechamente relacionados con las problemáticas que se generan en el Sub-continente. Tanto el desarrollo como su oponente, el subdesarrollo son temas de importancia en las agendas de los gobiernos de américa Latina, ellos no obvian que la mayoría de estos países se encuentran en una posición negativa, o como los llaman generalmente, países subdesarrollados. Se conoce que en los países de la región no existe un ingreso per cápita comparado al de los países del primer mundo, pero esto no significa que están totalmente atrasados, cada día los gobiernos latinoamericanos buscan alternativas para alcanzar el desarrollo, el problema son las alternativas planteadas para alcanzarlo.

Nicaragua no se ha quedado atrás para hacerle frente al tema del subdesarrollo, pero en lugar de enfocarse solo en el crecimiento económico, este ha ampliado las áreas o sectores en que se debe tomar empeño para alcanzar un desarrollo más humano. Es por ello, la creación del Plan Nacional de Desarrollo Humano, inspirado bajo un modelo socialista que tiene por objetivo principal el desarrollo delas personas de una manera completa e integral, destacando así la promoción de los valores que garanticen relaciones estrechas entre los ciudadanos Nicaragüenses, de ahí parte el programa Usura Cero, si bien este trabaja específicamente con mujeres, pero está claro que tienes repercusiones tanto en sus familias, comunidades y sociedad en general, el programa Usura Cero es esencial para combatir la pobreza, y garantizar de que todas y todos disfruten de sus derechos, es una base para el empoderamiento de las capacidades y habilidades de los individuos y a la vez es una herramienta con la cual se van cumpliendo los retos del milenio en Nicaragua.

\section{BIBLIOGRAFÍA}

Benavidez, O. (2012). Geografía de Nicaragua. Obtenido de TRIPOD: http://esteli.tripod.com/ geografi.htm

Cerón, T. (6 de Julio de 2016). Programa Usura Cero permite el crecimiento económico de las mujeres nicaragüenses. El 19 digital. (E. 1. digital, Ed.) Managua, Nicaragua. Obtenido de https://www. el19digital.com/articulos/ver/titulo:43869- 
programa-usura-cero-permite-el-crecimientoeconomico-de-las-mujeres-nicaraguenses

Corea, L. (10 deAgosto de 2014). La voz del Sandinismo. Obtenido de http://www.lavozdelsandinismo.com/ usura-cero/

El 19 digital. (9 de Octubre de 2015). Usura Cero da a conocer Plan de Cierre 2015 hacia un 2016 en Buena Esperanza. Managua, Nicaragua. Obtenido de https://www.el19digital.com/articulos/ver/ titulo:34418-usura-cero-da-a-conocer-plan-decierre-2015-hacia-un-2016-en-buena-esperanza

Felpudos. (2012). Historia del concepto de desarrollo sustentable. Obtenido de https://es.scribd.com/ doc/104683651/1-Historia-Del-Concepto-deDesarrollo-Sustentable

Griffin, K. (1998). Desarrollo humano: origen, evolucion eimpacto. Obtenido de http:/www. ciberoamericana.com/documentos/introcoopdes/ Desarrollo\%20Humano.\%20Origen, \%20 Evoluci\%23U00f3n,\%20Impacto.pdf

GRUN. (2012). Plan Nacional de Desarrollo Humano. 2012-2016. Managua, Nicaragua: GRUN. Obtenido de: http://www.pndh.gob.ni/documentos/ pndhActualizado/pndh.pdf

GRUN-MIFIC. (2008). Programa Usura Cero.
Plan de actividades 2008. Managua, Nicaragua. Obtenido de http://www.nicaraguatriunfa.com/ documentos2007/DICIEMBRE/USURA\%20 CERO\%202008.pdf

Hernandez, H. (2016). Desigualdades que enfrenan las mujeres. Obtenido de Mujer del mediterrraneo: http://mujerdelmediterraneo.heroinas.net/2016/01/ desigualdades-que-enfrentan-las-mujeres.html

La voz del sandinismo. (2016). Programa Usura Cero ha llegado a más de 180 mil mujeres en Nicaragua. Obtenido de La voz del sandinismo: http://www. lavozdelsandinismo.com/nicaragua/2016-07-07/ programa-usura-cero-ha-1legado-a-mas-de-180mil-mujeres-en-nicaragua/

Nicaragua Triunfa. (5 de Julio de 2010). Programa USURA CERO. Principales Avances al 30 de Junio 2010. (L. L. Sigue, Ed.) Managua, Nicaragua. Obtenido de http://www. laluchasigue.org/index.php? option $=\mathrm{com}$ content\&view $=$ article\&id=366: nicaragua

Vilas, C. (2008). ¿Qué estado para un desarrollo con equidad? Un comentario desde la teoria plítica. Obtenido de http://www.vocesenelfenix.com/sites/ default/files/pdf/Vilas.pdf 